\title{
Monitoramento de terminologia na mídia: o Programa Mais Médicos
}

\section{Terminology monitoring in the media: the Program More Doctors}

\author{
César Luz \\ César Nardelli Cambraia** \\ Eliane Dias Gontijo ${ }^{* * * *}$
}

Resumo: No presente estudo, analisa-se a cobertura da Fol ha de São Paulo em relação ao Programa Mais Médicos, no período de 28 de janeiro de 2013 a 30 de junho de 2014. Utiliza-se como método o monitoramento de 28 termos-chave extraídos dos objetivos da Lei $n^{\circ} 12.871$, de 22 de outubro de 2013, que instituiu o programa. Verificou-se que apenas dez dos 28 termos-chave estão entre os 100 lexemas mais frequentes no corpus. O monitoramento dos termos demonstrou-se capaz de comprovar o distanciamento da cobertura do jornal em relação aos objetivos da lei que instituiu o Programa Mais Médicos.

Palavras-chave: Saúde Pública; Terminologia; Programa Mais Médicos.

Abstract: In the present study we analyze the coverage of Folha de São Paulo regarding the Program More Doctors, from January $28^{\text {th }} 2013$ to June $30^{\text {th }} 2014$. The method used was the monitoring of 28 key terms extracted from the objectives of the Brazilian law nr. 12.871, of October $22^{\text {nd }} 2013$, which established the Program. It was found that only 10 of the 28 key terms are among the 100 most frequent lexemes in the corpus. The monitoring of terms proved to be able to show the distance of newspaper's coverage in relation to the objectives of the law which established the Program in Brazil.

\footnotetext{
* Mestre em Saúde Pública pela Faculdade de Medicina da UFMG. E-mail: cesar.luz700@gmail.com

** Professor Associado de Filologia Românica na Faculdade de Letras da UFMG. E-mail: nardelli@ufmg.br

*** Professora Titular do Departamento de Medicina Preventiva e Social da Faculdade de Medicina da UFMG. E-mail: egontijo@medicina.ufmg.br
} 
LuZ, C.; Cambrala, C. N.; GontiJo, E. D. - Monitoramento de terminologia na mídia: o Programa Mais Médicos

Keywords: Public Health; Terminology; More Doctors Program.

\section{Introdução}

O grande volume de informação em circulação em formato digital e as ferramentas da informática para processamento de dados permitem hoje analisar diferentes temas com grande rigor.

Se, no passado, a dependência da memória ou de anotações escritas dos pesquisadores aumentava o risco de viés nas análises em função da dificuldade de realizar um tratamento exaustivo dos dados, na atualidade, esse risco tem sido minorado em função da capacidade de processamento de ferramentas computacionais, como softwares de processamento.

Em se tratando de temas relacionados a campos de conhecimento especializado, há uma circunstância especialmente interessante para o emprego do processamento computacional: a existência de um vocabulário especializado, ou seja, de uma terminologia.

No presente artigo $^{1}$, realiza-se uma análise do tratamento dado pela mídia escrita (mais especificamente, pelo jornal Folha de São Paulo) ao Programa Mais Médicos, aplicando-se como método o monitoramento das suas unidades terminológicas específicas. Esta análise tem como objetivo avaliar se os temas discutidos na abordagem do referido jornal estão em sintonia com os objetivos do Programa enunciados na Lei no 12.871, de 22 de outubro de 2013, que o instituiu (BRASIL 2013a).

Diante da proliferação de textos com que utilizam jargão próprio, de alta densidade terminológica, Barros (2004) advoga que terminologia e jornalismo

\footnotetext{
1 Este artigo baseia-se em parte da dissertação de mestrado em Saúde Pública intitulada 0 Programa Mais Médicos em uma abordagem lexical: representação social e repercussão científica, defendida em maio de 2015, na Faculdade de Medicina da UFMG (LUz 2015).
} 
LUZ, C.; CAmbraiA, C. N.; GontiJo, E. D. - Monitoramento de terminologia na mídia: o Programa Mais Médicos

devem atuar em conjunto, aquela no levantamento e esclarecimento dos termos, com objetivo de auxiliar este na compreensão da problemática em questão para que se possa "explicar ao leitor, de modo simples, o que ocorre e, sobretudo, expor, com clareza, as principais consequências sobre esse mesmo público" (BARROS 2004: 96).

\section{O Programa Mais Médicos}

O Programa Mais Médicos (PMM), instituído pela Lei 12.871, de 22 de outubro de 2013 (BRASIL 2013a), regulamenta as condições para o funcionamento dos cursos de medicina, que não poderão prescindir de hospitais de ensino com, no mínimo, dez especialidades e certificado de qualidade atualizado.

A mesma lei cria o Projeto Mais Médicos para o Brasil (PMB), que recruta médicos formados no Brasil e em outros países para atuar na Atenção Básica. Determina, ainda, equivalência entre o número de formandos e de vagas de residência médica, até 2018. Disciplina que a certificação das especialidades, inclusive as concedidas por associações médicas, devem se submeter às prioridades do SUS. Com essa finalidade, o Ministério da Saúde manterá o Cadastro Nacional de Especialistas.

A primeira manifestação pública da Presidência da República Federativa do Brasil sobre a contratação de mais médicos ocorreu no Centro de Convenções Ulysses Guimarães, em Brasília-Distrito Federal, no dia 28 de janeiro de 2013, quando a presidente Dilma Rousseff, no discurso de abertura do Encontro Nacional com Novos Prefeitos e Prefeitas, fez um pronunciamento sobre o assunto (ROuSSEFF 2013).

Ilustrativo da posição já formada da Frente Nacional de Prefeitos (FNP) sobre a contratação de médicos foi um folheto digital com o seguinte texto: "PREFEITOS PEDEM AÇÕES IMEDIATAS PARA A CONTRATAÇÃO DE MÉDICOS FORMADOS EM OUTROS PAÍSES" (Blog Cadê o Médico 2013). 
LuZ, C.; Cambraia, C. N.; GontiJo, E. D. - Monitoramento de terminologia na mídia: o Programa Mais Médicos

A Presidência da República adota a Medida Provisória 621 (MP 621), em 8 de julho de 2013 (BRASIL 2013b), publicada no Diário Oficial da União no dia 9 de julho, que tem "força de lei", com base no art. 62 da Constituição Federal de 1988 (BRASIL 1988), instituindo o PMM.

Na Câmara Federal, a MP 621 foi objeto de intensos debates entre deputados e senadores governistas e oposicionistas na Comissão Mista criada exclusivamente para sua apreciação e que recebeu 567 proposições de mudança.

No Plenário da Câmara, foi aprovada a redação final do Projeto de Conversão 26, no dia 9 de outubro de 2013 (BRASIL 2013c), com significativas inclusões na redação final dada pelo relator Rogério Carvalho (PT-SE), principalmente nos Capítulos II (Da autorização para funcionamento dos cursos de medicina) e III (Da formação médica no Brasil). Também foi incluída no texto a emissão do registro profissional do médico intercambista, que passou a ser prerrogativa do Ministério da Saúde - com essa finalidade, a Presidência da República editou o Decreto 8.126, em 22 de outubro de 2013 (BRASIL 2013d).

O Segundo Ciclo, que elevaria a graduação em medicina para oito anos, com dois anos de serviços prestados ao SUS, foi excluído. No dia 16 de outubro, o Senado Federal aprovou o texto elaborado na Câmara, sem modificações. 0 Parecer 1.143 (BRASIL 2013e), da Comissão Diretora do Senado, seguiu para a sanção da Presidência da República, que vetou somente o parágrafo primeiro do Artigo 16, que vedava ao médico intercambista o exercício da medicina fora das atividades do PMB, sancionando a Lei $\mathrm{n}^{\circ} 12.871$, no dia 22 de outubro de 2013 (BRASIL 2013a).

Balanço do Ministério da Saúde afirma que, desde a sua criação em julho de 2013, o PMM incorporou 14.462 médicos, em 3.785 municípios (68\% do total), e nos 34 Distritos Sanitários Especiais Indígenas, beneficiando cerca de 50 milhões de brasileiros (DAB 2015). Em press release da Agência Saúde (DAB 2015), assegura-se que $R \$ 5,6$ bilhões foram destinados para construções, ampliações e reformas de Unidades Básicas de Saúde (UBS); informa que já foram autorizadas 4.460 novas vagas de graduação em cursos de medicina 
Luz, C.; CambralA, C. N.; GontiJo, E. D. - Monitoramento de terminologia na mídia: o Programa Mais Médicos

(3.117 em instituições de ensino superior privadas e 1.343 em instituições públicas) e 2.822 novas vagas em residência médica, no ano de 2014.

\section{Terminologia}

A Terminologia é, segundo Barros (2004: 21), a "disciplina científica que estuda as chamadas línguas (...) de especialidade e seu vocabulário”. Cada unidade que forma esse vocabulário é chamada de termo ou unidade terminológica, que pode ser definida como "uma unidade lexical com um conteúdo específico dentro de um domínio específico” (BARROS 2004: 40).

Do ponto de vista de classe, esclarece Barros (2004: 100) que "a classe lexical de base nominal (substantivos) ocupa lugar de destaque nos estudos em línguas de especialidade".

A propósito da espinhosa tarefa de reconhecer o estatuto terminológico de unidades lexicais, Krieger (2000: 226) assinala que:

os parâmetros clássicos tornaram-se insuficientes e inadequados diante da diversidade das tipologias terminológicas, em sua maioria, constituídas ao modo de sintagmas nominais. Todos os problemas relacionados à identificação dos termos recrudescem porque as unidades lexicais, de alta produtividade nesta época de acelerado desenvolvimento da ciência e da tecnologia, não apenas proliferamse intensamente, como cruzam as fronteiras dos diferentes discursos especializados.

Em face disso, Krieger (2000: 222) sugere que:

a consideração pelas formas de produção de significação, constitutivas e particulares às diferentes manifestações do homem, torna-se importante recurso metodológico para o reconhecimento do estatuto terminológico de uma unidade lexical, que sempre cobra sentido pela sua relação a um campo de conhecimento.

A Terminologia também classifica os termos em "simples", formados por 
Luz, C.; CambralA, C. N.; GontiJo, E. D. - Monitoramento de terminologia na mídia: o Programa Mais Médicos

apenas um radical, com ou sem afixos, e "complexos", constituídos de dois ou mais radicais, que podem receber complementos (BARROS 2004). A autora esclarece que os termos "compostos" (por exemplo, mão de obra), distinguemse dos termos "complexos", porque aqueles apresentam alto grau de lexicalização, em que os morfemas lexicais ou gramaticais que os constitui apresentam situação de não-autonomia, representada graficamente pelo hífen. Os sintagmas terminológicos são lexicalizados (exemplos: Via Láctea, Estrada de Santiago, estrada de rodagem), ao passo que os sintagmas livres apresentam baixa estabilidade (exemplo: elemento propulsor para embarcações de baixo calado).

Segundo Barros (2004), "a lexicalização se caracteriza como um processo que vai da sintaxe ao léxico, no qual uma sequência de unidades lexicais transforma-se em uma única unidade léxico-semântica". De forma semelhante a Biderman (2001), os principais testes para se aferir a lexicalização dos sintagmas terminológicos, sem perda dos respectivos sentidos, são: (a) a não autonomia (exemplo: quinta-feira); (b) a impossibilidade de comutação (exemplo: mesa-redonda); (c) a não separabilidade (exemplo: terra fina) e (d) a particularidade da estrutura interna (exemplo: fazer justiça, de bom tamanho).

A existência de uma definição especializada para o sintagma analisado é outro critério importante na avaliação do grau de lexicalização de um termo sintagmático. A pergunta que se deve fazer ao se aplicar tal critério é: a sequência sintagmática em questão designa um conceito em particular? Se a resposta for afirmativa, essa sequência é um termo sintagmático. 0 mesmo critério serve para verificar se unidades lexicais são ou não termos (BARROs 2004: 103).

A frequência de co-ocorrências (mesma associação de palavras), segundo a autora, é outro critério importante para se verificar o grau de lexicalização de um sintagma. Também ajuda a provar a lexicalização a maneabilidade (facilidade do uso), a imprevisibilidade semântica (dos sintagmas separados), a estabilidade em oposição aos hápax (termos que aparecem uma única vez em 
Luz, C.; CambralA, C. N.; GontiJo, E. D. - Monitoramento de terminologia na mídia: o Programa Mais Médicos

um corpus analisado) e o uso prolongado, que conduz a uma integração semântico-sintática muito forte e à memorização por parte dos usuários. 0 sintagma adquire, assim, uma estabilidade de forma e de sentido.

De acordo com a autora, o conjunto terminológico presente em um texto constitui um subconjunto vocabular, em que a produção de novos termos se faz a partir de um hiperônimo, que funciona como um "lexema base"2 (BARROS 2004: 101), em direção aos hipônimos, termos mais específicos (exemplo: raio, raio gama, raio laser, raio infravermelho, raio ultravioleta). Assim, enquanto a lexicografia elabora dicionários de língua ou especiais, a terminografia elabora dicionários especializados, que têm como entrada principal a unidade lexical, registrando-se exclusivamente as acepções (semas) que assumem para áreas específicas do saber.

Barros (2004) esclarece que a Teoria Geral da Terminologia (TGT), da qual Eugen Wüster (1898-1977) é considerado o precursor, apresenta como princípio a univocidade entre conceito e termo (um termo para um conceito), o que eliminaria ruídos, não se admitindo termos polissêmicos, sinônimos ou homônimos e, para tanto, dissocia os termos do léxico, da gramática, do contexto e do discurso (pragmática).

Diferencia-se da Teoria Comunicativa da Terminologia (TCT), desenvolvida por Maria Teresa Cabré, cujo foco está nas dimensões textual e discursiva dos termos, que, assim, não existiriam per se: "a unidade lexical torna-se termo (assume o valor de termo) de acordo com o uso em um contexto expressivo e comunicacional específico" (CABRÉ 1999: 124 apud BARROs 2004: 57). Assim, segundo Barros (2004), na TCT, são admitidas a homonímia, a polissemia e a variação linguística (léxica) e, além da perspectiva expressiva, a TCT analisa os termos a partir do seu conteúdo (análise conceptual ou conceitual).

Dentro de um sistema conceptual, o valor de um termo é dado pelo lugar que ocupa na estrutura, podendo ocupar lugares diferentes, de acordo com os critérios de organização do sistema de conceitos. Os

\footnotetext{
${ }^{2}$ No quadro da lexicologia, lexema é definido como a unidade léxica abstrata da língua e lexia como a manifestação discursiva do lexema (BIDERMAN 2001).
} 
LuZ, C.; Cambrala, C. N.; GontiJo, E. D. - Monitoramento de terminologia na mídia: o Programa Mais Médicos

termos não pertencem a um domínio, mas são usados em um domínio com um valor singularmente específico". (CABRÉ 1999: 124 apud BARROS 2004: 58)

Nesse tipo de análise (conceptual ou conceitual), os "contextos" de ocorrência (dos termos) são tomados como enunciados que exprimem uma ideia completa do termo, cujas características são identificadas por meio dos "descritores". Para elucidação concreta, a autora toma o contexto explicativo do ciclamato: "também sintético e não calórico, contém ácidos, cálcio e sódio. Adoça quarenta vezes mais do que o açúcar". Esclarece que, a partir desse contexto explicativo, foram eleitos os seguintes elementos linguísticos como descritores, capazes de exprimir as características do ciclamato como edulcorante: sintético; não calórico; (contém) ácidos; (contém) cálcio; (contém) sódio; adoça quarenta vezes mais do que o açúcar (BARROs 2004: 109).

\section{Hipótese de trabalho}

Será testada a hipótese de que a presença e a frequência de terminologia da área de Saúde Pública permitem analisar o tratamento dado pela Folha de São Paulo ao Programa Mais Médicos, assumindo-se que os termos técnicos são imprescindíveis para discussões consistentes em campos especializados do conhecimento.

\section{Metodologia}

A presente pesquisa em terminologia, de base empírica, adota conceitos enquadrados atualmente na Linguística de Corpus, ou seja, em uma abordagem 
LUZ, C.; CAmbraiA, C. N.; GontiJo, E. D. - Monitoramento de terminologia na mídia: o Programa Mais Médicos

da análise linguística tomando como referência um corpus de textos (SARDINHA 2000, LEón 2006).

Um corpus para análises linguísticas é:

[u]m conjunto de dados linguísticos (pertencentes ao uso oral ou escrito da língua, ou a ambos), sistematizados segundo determinados critérios, suficientemente extensos em amplitude e profundidade, de maneira que sejam representativos da totalidade do uso linguístico ou de algum de seus âmbitos, dispostos de tal modo que possam ser processados por computador, com a finalidade de propiciar resultados vários e úteis para a descrição e análise (SANCHEZ 1995 apud SARDINHA 2000: 338).

Foi eleita a Folha de São Paulo (FSP) como fonte para constituição do corpus de análise, uma vez que apresenta a segunda maior média de circulação do Brasil, com 294.811 exemplares diários, em 2013, de acordo com dados do Instituto Verificador de Circulação (IVC), disponibilizados pela Associação Nacional dos Jornais (ANJ, 2014). O primeiro no ranking, Super Notícia, de Minas Gerais, com tiragem média diária de 302.472 , é de perfil popular e prioriza coberturas mais sensacionalistas, que não incluem o tema deste artigo.

Levando em conta esses dados, percebe-se que a FSP é um jornal relevante do ponto de vista de circulação e, em função disso, deve ser priorizado em análises que tenham como objetivo verificar como a mídia trata diferentes temas.

A busca sobre o PMM na FSP por meio do serviço de consulta ao clipping digital do Ministério da Saúde apontou inconsistência nos resultados obtidos, quando se comparava o quantitativo de publicações face ao obtido diretamente no site da FSP: o número de resultados do clipping (116 publicações) era muito inferior ao obtido diretamente no site (916 publicações). Assim, decidiu-se realizar a busca diretamente no site do jornal (www.uol.folha.com.br), utilizando a expressão "Mais Médicos" (entre aspas e com as iniciais maiúsculas), no período de 28 de janeiro de 2013 a 30 de junho de 2014, que foi estabelecido como marco final, tendo em vista a exequibilidade da presente pesquisa. 
Luz, C.; CambralA, C. N.; GontiJo, E. D. - Monitoramento de terminologia na mídia: o Programa Mais Médicos

Como a sanção da Lei no 12.871 pela Presidência da República demarca o início efetivo de implantação do PMM, estabeleceu-se uma linha de corte do período que vai do dia 28 de janeiro (data da manifestação pública da Presidência da República no encontro da FNP) a 21 de outubro, constituindose, dessa forma, o Subcorpus A; o Subcorpus B inicia-se em 22 de outubro de 2013 (sanção da Lei 12.871) e estende-se até 30 de junho de 2014 (prazo máximo exequível para a pesquisa).

O corpus incluiu todo elemento textual, como reportagens, notas, colunas, legendas de fotos, artigos, entrevistas e editoriais, excluindo-se os elementos de informação visual (fotografias, infográficos, vídeos, gráficos e tabelas), que não podem ser processados diretamente pelo programa de análise, além de informação verbal que pode gerar viés na análise, como nome dos autores (sejam os redatores jornalistas ou não), local da publicação, mensagens publicitárias que acompanham os textos, ícones de redes sociais, hiperlinks e outros. Após esse processo de depuração, cada arquivo de texto contém, tão-somente, o título e o corpo do texto a ser analisado, além da legenda da foto, quando esta ocorre.

Assim estruturado, o corpus linguístico deste estudo, de acordo com Sardinha (2000), atinge, pelo critério de classificação, a categoria de "pequenomédio" (de 80 mil a 250 mil palavras), considerando-se o total de tokens ${ }^{3}$ (178.860) obtidos. Deve-se assinalar, no entanto, que, em função do progresso tecnológico, essa classificação foi relativizada, pois hoje em dia é possível compilar corpora com volume muito maior de palavras sem muita dificuldade, o que significa que a noção de médio provavelmente se aplica hoje a corpora de extensão bem maior do que 250 mil palavras. Com base no mesmo autor, conclui-se que o corpus de análise do estudo pode ser tomado (SARDINHA 2000)

\footnotetext{
${ }^{3}$ Adotamos aqui o termo em inglês que se usa frequentemente em programas de processamento de linguagem, como o empregado na presente pesquisa (a ser informado mais adiante). Uma equivalência terminológica dos principais termos desses programas entre a forma inglesa e uma portuguesa seria: lemma = lexema; type = lexia e token = cada ocorrência de uma lexia.
} 
LUZ, C.; CAmbraiA, C. N.; GontiJo, E. D. - Monitoramento de terminologia na mídia: o Programa Mais Médicos

como: fechado; autêntico; escrito; diacrônico; especializado; de autoria plural; de estudo.

Embora a presente análise contemple também o vocabulário geral dos dois subcorpora, seu cerne está nos termos-chave, ou seja, nos termos técnicos da área de saúde pública que serão investigados no corpus por representarem aspectos essenciais.

Visto que o tema de estudo é o PMM, mostra-se como de grande relevância como parâmetro para a análise a terminologia utilizada na própria Lei $n^{\circ} 12.871$. Assim, optou-se por se eleger dos seus objetivos (presentes no Cap. I, art. $1^{\circ}$, incisos I a VII) 28 substantivos extraídos como termos-chave, pertinentes à área da saúde pública. Esses termos-chave foram extraídos manualmente após leitura atenta da referida lei. Reproduzem-se abaixo o caput do Art. $1^{\circ}$ e os referidos incisos, colocando-se em negrito os termos-chave eleitos para análise:

Quadro 1 - Termos-chave da Lei 12.871 e expressão de busca

\begin{tabular}{|l|l|}
\hline Termos-chave & Expressão de busca \\
\hline $\begin{array}{l}\text { Art. } 1^{\circ} \text { E instituído o Programa Mais Médicos, com a } \\
\text { finalidade de formar recursos humanos na área } \\
\text { médica para o Sistema Único de Saúde (SUS) e com } \\
\text { os seguintes objetivos: }\end{array}$ & $\begin{array}{l}\text { RECURSO* } \\
\text { SISTEMA ÚNICO DE SAÚDE/ } \\
\text { SUS }\end{array}$ \\
\hline $\begin{array}{l}\text { I - diminuir a carência de médicos nas regiões } \\
\text { prioritárias para o SUS, a fim de reduzir as as } \\
\text { desigualdades regionais na área da saúde; }\end{array}$ & $\begin{array}{l}\text { CARÊNCIA* } \\
\text { REGIÃO/ REGIÕES } \\
\text { DESIGUALDADE* } \\
\text { SAÚDE }\end{array}$ \\
\hline $\begin{array}{l}\text { II - fortalecer a prestação de serviços de atenção } \\
\text { básica em saúde no País; }\end{array}$ & $\begin{array}{l}\text { PRESTAÇ* } \\
\text { SERVIÇO* } \\
\text { ATENÇ* }\end{array}$ \\
\hline $\begin{array}{l}\text { III - aprimorar a formação médica no País e } \\
\text { proporcionar maior experiência no campo de prática } \\
\text { médica durante o processo de formação; }\end{array}$ & $\begin{array}{l}\text { FORMAÇ } \\
\text { EXPERIÊNCIA* } \\
\text { PRÁTIC* }\end{array}$ \\
\hline $\begin{array}{l}\text { IV - ampliar a inserção do médico em formação nas } \\
\text { unidades de atendimento do SUS, desenvolvendo seu } \\
\text { conhecimento sobre a realidade da saúde da } \\
\text { população brasileira; }\end{array}$ & $\begin{array}{l}\text { INSERÇ* } \\
\text { ATENDIMENTO* } \\
\text { CONHECIMENTO* } \\
\text { REALIDADE* } \\
\text { POPULAÇ** }\end{array}$ \\
\hline
\end{tabular}


LuZ, C.; Cambrala, C. N.; GontiJo, E. D. - Monitoramento de terminologia na mídia: o Programa Mais Médicos

\begin{tabular}{|c|c|}
\hline $\begin{array}{l}\text { V - fortalecer a política de educação permanente com } \\
\text { a integração ensino-serviço, por meio da atuação das } \\
\text { instituições de educação superior na supervisão } \\
\text { acadêmica das atividades desempenhadas pelos } \\
\text { médicos; }\end{array}$ & $\begin{array}{l}\text { POLITIC** } \\
\text { EDUCAÇ* } \\
\text { INTEGRAÇ* } \\
\text { ENSINO** } \\
\text { ATUAÇ* } \\
\text { SUPERVIS* }\end{array}$ \\
\hline $\begin{array}{l}\mathrm{VI} \text { - promover a troca de conhecimentos e } \\
\text { experiências entre profissionais da saúde brasileiros e } \\
\text { médicos formados em instituições estrangeiras; }\end{array}$ & $\begin{array}{l}\text { TROCA }^{*} \\
\text { PROFISSIONA* }^{*}\end{array}$ \\
\hline $\begin{array}{l}\text { VII - aperfeiçoar médicos para atuação nas políticas } \\
\text { públicas de saúde do País e na organização e no } \\
\text { funcionamento do SUS; }\end{array}$ & $\begin{array}{l}\text { ORGANIZAÇ* } \\
\text { FUNCIONAMENTO* }\end{array}$ \\
\hline $\begin{array}{l}\text { VIII - estimular a realização de pesquisas aplicadas ao } \\
\text { SUS. }\end{array}$ & PESQUISA* \\
\hline
\end{tabular}

Para o processamento dos textos, utilizou-se o Programa AntConc (versão para Windows 3.2.4), de Laurence Anthony (Universidade de Waseda, Japão). A expressão de busca incluiu o asterisco para que se captassem as formas flexionadas de gênero e/ou número.

Considerando que os dois subcorpora não são compostos do mesmo número de textos e, consequentemente, do mesmo número de ocorrências dos termos, ou seja, de tokens, foi necessário aplicar alguns procedimentos estatísticos para tornar a análise equilibrada.

Primeiramente, o número de ocorrências de cada termo-chave foi relativizado em função do número de tokens: assim, por exemplo, o termochave RECURSO ocorre 93 vezes tanto no S-A quanto no S-B, mas o valor que representa é diferente, pois é 0,0975 no S-A $(93 / 95.396)$ e 0,1114 no S-B (93/83.464).

Para dar maior confiança à comparação entre os valores do S-A e do S-B, adotou-se o método de razão de prevalências para avaliar a significância estatística, calculando-se o intervalo de confiança a 95\% (Dever 1984). Por esse método, obtém-se como resultado a significância estatística para a razão de prevalência entre as ocorrências no Subcorpus $B$ ( $r 1)$, em relação ao Subcorpus A (r2). Para tanto, toma-se como Hipótese Nula (H0) r1 = r2 e como Hipótese Alternativa $(\mathrm{H} 1) \mathrm{r} 1 \neq \mathrm{r} 2$. Na sequência de cálculos para se obterem 
Luz, C.; CambralA, C. N.; GontiJo, E. D. - Monitoramento de terminologia na mídia: o Programa Mais Médicos

tais resultados, como primeiro passo, toma-se a frequência absoluta das ocorrências (numerador) e o total de tokens em cada subcorpus (denominador), obtendo-se a prevalência respectiva em S-A e S-B. A seguir, aplica-se a razão de prevalências de S-B (numerador) sobre S-A (denominador), uma vez que o que se busca é a elevação/redução ou equivalência das ocorrências no S-B, em relação às ocorrências no S-A. Interpreta-se o $\mathrm{IC}_{95 \%}$, observando-se se $\mathrm{O}$ resultado inclui a unidade entre o limite inferior e o limite superior do intervalo (equivalência), se é menor do que um (redução) ou se é maior que um (elevação).

\section{Descrição e discussão dos dados}

Uma primeira análise pode ser feita considerando o número de publicações sobre o PMM na FSP no período estudado: a oscilação para mais ou para menos revelará qual é a importância dada por esse meio de comunicação ao tema.

As buscas resultaram em 601 publicações no Subcorpus A (S-A) e 391 no Subcorpus B (S-B), das quais foram excluídas 76 por não consistirem em referência ao PMM ou por serem artigos com conteúdo que não se referia diretamente a esse Programa. Passaram a compor, definitivamente, o corpus de análise deste estudo 916 publicações, com 533 no S-A e 383, no S-B.

O corpus está composto de 178.860 tokens, dos quais 95.396 tokens no S-A e 83.464 tokens no S-B. Este resultado foi obtido após a aplicação de uma lista de exclusão constituída por palavras gramaticais (artigos, pronomes, numerais, conjunções, preposições, interjeições, advérbios) e pelos verbos ser, estar, ter e haver (frequentemente utilizados como auxiliares).

Tabela 1 - Frequência mensal de publicações e total de tokens no S-A 
LUZ, C.; Cambrala, C. N.; GontiJo, E. D. - Monitoramento de terminologia na mídia: o Programa Mais Médicos

\begin{tabular}{c|cc}
\hline Ano & Mês & Quantidade de Publicações \\
\hline \multirow{4}{*}{2013} & Janeiro & 0 \\
& Fevereiro & 0 \\
& Março & 0 \\
& Abril & 0 \\
& Maio & 4 \\
& Junho & 4 \\
& Julho & 103 \\
& Agosto & 175 \\
& Setembro & 186 \\
& Outubro & 61 \\
\hline & Total & $\mathbf{5 3 3}$ \\
\hline & Tokens & $\mathbf{9 5 . 3 9 6}$ \\
\hline
\end{tabular}

Tabela 2 - Frequência mensal de publicações e total de tokens no S-B

\begin{tabular}{c|c|c}
\hline \multicolumn{2}{c}{ S-B } \\
\hline Ano & Mês & Quantidade de Publicações \\
\hline \multirow{3}{*}{2013 Outubro } & 27 \\
& Novembro & 67 \\
& Dezembro & 36 \\
& Janeiro & 28 \\
& Fevereiro & 77 \\
2014 & Março & 58 \\
& Abril & 47 \\
& Maio & 23 \\
& Junho & 20 \\
\hline Total & $\mathbf{3 8 3}$ \\
\hline Tokens & $\mathbf{8 3 . 4 6 4}$
\end{tabular}

Os gráficos a seguir registram a ocorrência de publicações que atenderam à expressão de busca "Mais Médicos" no período de 28/01/2013 a 30/06/2014, divididos por subcorpora, levando-se em consideração a ocorrência de eventos relevantes para a investigação do desenvolvimento da cobertura da imprensa sobre o tema, inclusive, indicando-se pesquisas de opinião divulgadas pelo jornal FSP. 
LuZ, C.; Cambrala, C. N.; GontiJo, E. D. - Monitoramento de terminologia na mídia: o Programa Mais Médicos

Gráfico 1 - Frequência absoluta mensal de textos com a expressão de busca "Mais Médicos" na FSP (S-A)

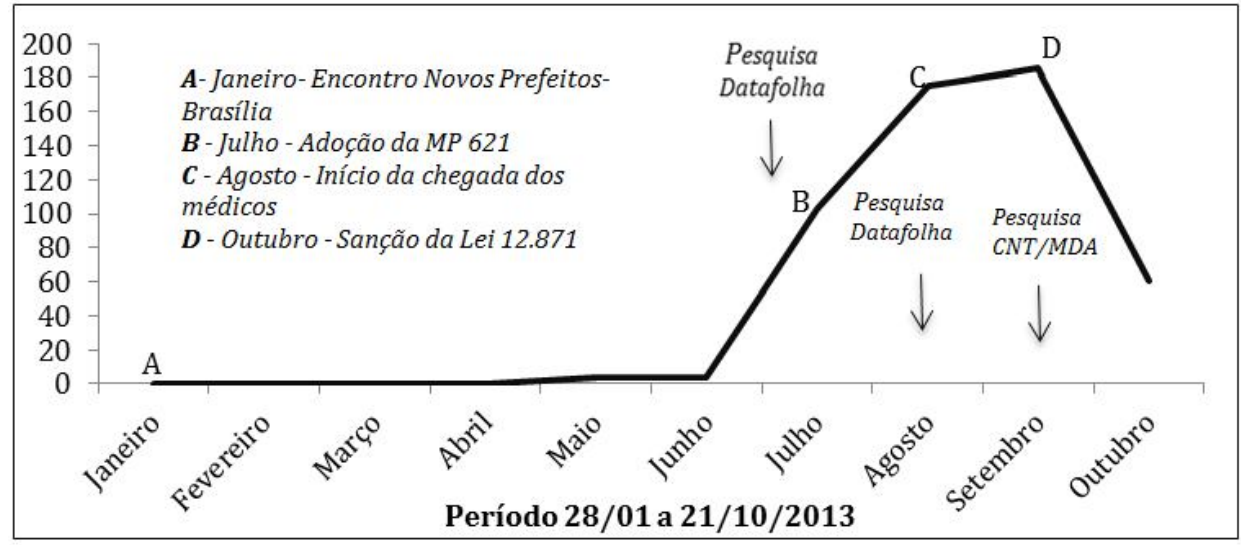

Gráfico 2 - Frequência absoluta mensal de textos com a expressão de busca "Mais Médicos" na FSP (S-B)

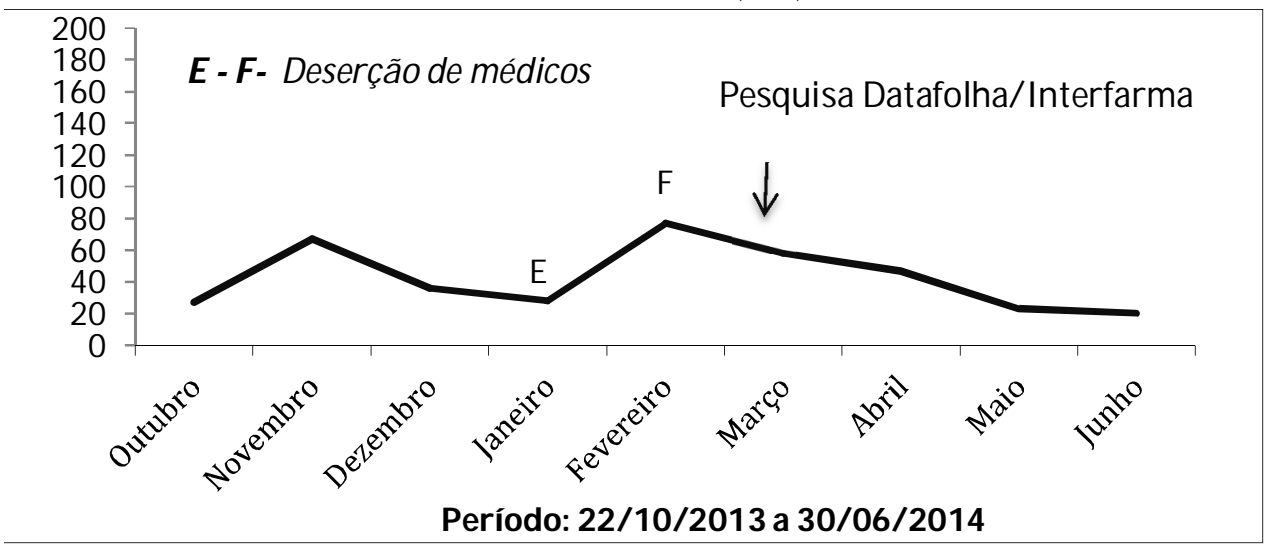

Pesquisas realizadas e referenciadas nos gráficos acima:

(a) Pesquisa Datafolha ${ }^{4}$ ("País se divide sobre uso de médico estrangeiro"): complementada pelo subtítulo "Proposta do governo federal de trazer profissionais de saúde de fora do Brasil tem apoio de $47 \%$ e rejeição de 48\%"). Realizada pelo Datafolha, informa que a aprovação cresce entre os mais jovens $(51 \%)$, os menos escolarizados $(56 \%)$, mais pobres $(54 \%)$ e entre os

4 Disponível em: www1.folha.uol.com.br/cotidiano/2013/08/1324760-aumenta-aprovacao-acontratacao-de-medicos-estrangeiros-no-pais.shtml. Acesso em:18 jan. 2015. 
Luz, C.; CambralA, C. N.; GontiJo, E. D. - Monitoramento de terminologia na mídia: o Programa Mais Médicos

moradores do Nordeste (56\%). A pesquisa foi realizada em 27-28 de junho, em 196 municípios, ouvindo 4.717 entrevistados.

(b) Pesquisa Datafolha 5 ("Aumenta a aprovação à contratação de médicos estrangeiros no Brasil"): realizada entre 7 e 9 de agosto; 2.615 entrevistas em 160 cidades; publicada em 12 de agosto de 2013; 54\% de aprovação ao Programa, contra 47\% verificados no final de junho; traça o perfil de quem apoia e quem é contra a "vinda de médicos estrangeiros".

(c) Pesquisa CNT/MDA ${ }^{6}$ (“Mais Médicos ajuda Dilma a recuperar aprovação perdida em protestos, diz pesquisa”): realizada a pedido da Confederação Nacional dos Transportes (CNT) pelo Instituto MDA, entre 31 agosto e 4 de setembro de 2013; publicada em 10 de setembro 2013; 73,9\% dos entrevistados são favoráveis à contratação de médicos estrangeiros, enquanto a coleta anterior deste mesmo instituto, em julho, apresentou como favoráveis $49,7 \%$.

d) Pesquisa Datafolha/Interfarma7 (“14 milhões já foram atendidos por médico estrangeiro, diz Datafolha"): publicada em 27 de março de 2014; das pessoas atendidas, $69 \%$ consideraram o atendimento dos médicos estrangeiros ótimo ou bom e $67 \%$ aprovaram a vinda dos profissionais de outros países.

Analisando os dados da frequência de publicações sobre o PMM na FSP, verifica-se que, houve, inicialmente, uma expressiva elevação logo após a edição da MP 621, como seria de se esperar. Mas após a conversão da MP em Lei, a frequência diminui sensivelmente. Uma interpretação possível é a de que a FSP considerou importante dar especial atenção ao PMM apenas no período em que a MP ainda poderia ser alterada ou até rejeitada (julho a outubro). Uma segunda interpretação é a de que as sucessivas aprovações do PMM, mensuradas pela Pesquisa Datafolha de 12/08/13 (54\% de aprovação) e Pesquisa CNT/MDA

${ }^{5}$ Disponível em: www1.folha.uol.com.br/cotidiano/2013/08/1324760-aumenta-aprovacao-acontratacao-de-medicos-estrangeiros-no-pais.shtml. Acesso em:18 jan. 2015.

6 Disponível em: www1.folha.uol.com.br/poder/2013/09/1339709-dilma-recupera-parte-depopularidade-perdida-apos-protestos-aponta-pesquisa.shtml. Acesso: 18 jan. 2015.

7 Disponível em: www1.folha.uol.com.br/cotidiano/2014/03/1431554-14-milhoes-ja-foramatendidos-por-medico-estrangeiro-diz-datafolha.shtml. Acesso em: 18 jan. 2015. 
LUZ, C.; CambraiA, C. N.; GontiJo, E. D. - Monitoramento de terminologia na mídia: o Programa Mais Médicos

de 10/09/13 (73,9\% favoráveis), teria levado a considerar a pauta menos importante (daí menos publicações).

Uma segunda análise dos dados pode ser feita comparando-se os 100 lexemas nominais (substantivos e adjetivos) mais frequentes no corpus com a lista dos 28 termos-chave. Essa comparação tem como objetivo ver se as questões expressas pelos termos-chave, ou seja, os objetivos do PMM, recebem a devida atenção nas matérias da FSP. Apresenta-se a seguinte lista dos 100 lexemas nominais mais frequentes no corpus. 
LuZ, C.; Cambrala, C. N.; GontiJo, E. D. - Monitoramento de terminologia na mídia: o Programa Mais Médicos

Tabela 3 - 100 lexemas nominais mais frequentes no corpus

\begin{tabular}{|c|c|c|c|c|c|c|}
\hline \multirow[b]{3}{*}{ RANKING } & \multicolumn{2}{|c|}{ CORPUS } & \multicolumn{4}{|c|}{ SUBCORPORA } \\
\hline & & & \multicolumn{2}{|r|}{ A } & \multicolumn{2}{|r|}{ B } \\
\hline & FREQUÊNCIA & LEXEMA & FREQUÊNCIA & LEXEMA & FREQUÊNCIA & LEXEMA \\
\hline 1 & 6636 & MÉDICO & 4197 & MÉDICO & 2439 & MÉDICO \\
\hline 2 & 2421 & PROGRAMA & 1388 & SAÚDE & 1147 & PROGRAMA \\
\hline 3 & 2388 & SAÚDE & 1274 & PROGRAMA & 1073 & GOVERNO \\
\hline 4 & 2263 & GOVERNO & 1190 & GOVERNO & 1000 & SAÚDE \\
\hline 5 & 1447 & PROFISSIONAL & 884 & PROFISSIONAL & 701 & DILMA \\
\hline 6 & 1234 & CUBANO & 638 & PAís & 657 & CUBANO \\
\hline 7 & 1174 & PAís & 631 & FEDERAL & 612 & PRESIDENTE \\
\hline 8 & 1161 & DILMA & 605 & BRASILEIRO & 563 & PROFISSIONAL \\
\hline 9 & 1149 & PRESIDENTE & 577 & CUBANO & 553 & BRASIL \\
\hline 10 & 1108 & BRASIL & 557 & ANO & 536 & PAís \\
\hline 11 & 1053 & BRASILEIRO & 555 & BRASIL & 484 & ANO \\
\hline 12 & 1041 & ANO & 537 & PRESIDENTE & 447 & BRASILEIRO \\
\hline 13 & 1034 & FEDERAL & 524 & ESTRANGEIRO & 403 & FEDERAL \\
\hline 14 & 828 & MINISTÉRIO & 519 & MINISTÉRIO & 340 & PÚBLICO \\
\hline 15 & 703 & MEDICINA & 507 & MEDICINA & 323 & MINISTRO \\
\hline 16 & 666 & ESTRANGEIRO & 460 & DILMA & 309 & MINISTÉRIO \\
\hline 17 & 645 & MINISTRO & 408 & CONSELHO & 304 & PAULO \\
\hline 18 & 611 & CIDADE & 406 & CIDADE & 297 & PT \\
\hline 19 & 532 & PAULO & 355 & REGISTRO & 243 & CUBA \\
\hline 20 & 526 & CONSELHO & 334 & MUNICÍPIO & 243 & PADILHA \\
\hline 21 & 523 & PÚBLICO & 322 & MINISTRO & 208 & TRABALHO \\
\hline 22 & 520 & PADILHA & 277 & PADILHA & 207 & DIA \\
\hline 23 & 495 & CUBA & 273 & PÚBLICO & 205 & CIDADE \\
\hline 24 & 484 & PT & 272 & MEDIDA & 196 & MEDICINA \\
\hline 25 & 476 & DIA & 269 & DIA & 195 & ROUSSEFF \\
\hline 26 & 462 & TRABALHO & 254 & TRABALHO & 189 & $M \hat{E} S$ \\
\hline 27 & 398 & REGISTRO & 252 & CUBA & 189 & POLÍTICA \\
\hline 28 & 383 & MUNICÍPIO & 237 & EXTERIOR & 173 & CASA \\
\hline 29 & 365 & POPULAÇÃO & 236 & SEMANA & 165 & NACIONAL \\
\hline 30 & 362 & SEMANA & 228 & PAULO & 165 & POPULAÇÃO \\
\hline 31 & 360 & ROUSSEFF & 216 & INTERIOR & 152 & LULA \\
\hline 32 & 340 & NACIONAL & 204 & FORMADO & 147 & PESSOA \\
\hline 33 & 336 & MEDIDA & 200 & POPULAÇÃO & 145 & CAMPANHA \\
\hline
\end{tabular}

TradTerm, São Paulo, v. 25, Agosto/2015, pp. 199-233 
LUZ, C.; Cambrala, C. N.; GontiJo, E. D. - Monitoramento de terminologia na mídia: o Programa Mais Médicos

\begin{tabular}{|c|c|c|c|c|c|c|}
\hline 34 & 322 & $M \hat{E} S$ & 190 & ÁREA & 142 & ESTRANGEIRO \\
\hline 35 & 307 & EDUCAÇÃO & 187 & PT & 142 & MUNICÍPIO \\
\hline 36 & 303 & ÁREA & 186 & PROVISÓRIA & 142 & PSDB \\
\hline 37 & 303 & EXTERIOR & 185 & ENTIDADE & 138 & PARTE \\
\hline 38 & 288 & INTERIOR & 180 & EDUCAÇÃO & 138 & RAMONA \\
\hline 39 & 284 & PARTE & 175 & NACIONAL & 137 & AÇÃO \\
\hline 40 & 282 & POLÍTICA & 173 & SUS & 130 & ESTADO \\
\hline 41 & 281 & CASA & 165 & ROUSSEFF & 127 & CÂMARA \\
\hline 42 & 273 & CÂMARA & 158 & CONGRESSO & 127 & EDUCAÇÃO \\
\hline 43 & 270 & CONGRESSO & 154 & AÇÃO & 127 & VIDA \\
\hline 44 & 265 & FORMADO & 154 & PROPOSTA & 126 & SEMANA \\
\hline 45 & 260 & SUS & 151 & DIPLOMA & 123 & FOLHA \\
\hline 46 & 247 & ALEXANDRE & 149 & ALEXANDRE & 121 & ELEITORAL \\
\hline 47 & 244 & FOLHA & 146 & CÂMARA & 113 & ÁREA \\
\hline 48 & 234 & PROJETO & 140 & SISTEMA & 112 & CONGRESSO \\
\hline 49 & 234 & PROPOSTA & 137 & CURSO & 110 & BOLSA \\
\hline 50 & 229 & ENTIDADE & 134 & PROJETO & 107 & FAMÍLIA \\
\hline 51 & 229 & ESTADO & 134 & TEXTO & 106 & ATENDIMENTO \\
\hline 52 & 229 & VAGA & 133 & GRANDE & 105 & DISCURSO \\
\hline 53 & 224 & MAIOR & 128 & VAGA & 103 & RELAÇÃO \\
\hline 54 & 222 & DIPLOMA & 127 & MAIOR & 102 & SALÁRIO \\
\hline 55 & 222 & LULA & 126 & JUSTIÇA & 101 & CRÍTICA \\
\hline 56 & 222 & PESSOA & 121 & FOLHA & 101 & VAGA \\
\hline 57 & 218 & GRANDE & 116 & LEI & 100 & CHIORO \\
\hline 58 & 215 & SISTEMA & 114 & CONDIÇÃO & 100 & PROJETO \\
\hline 59 & 207 & ATENDIMENTO & 112 & REVALIDAÇÃO & 99 & GOVERNADOR \\
\hline 60 & 205 & ELEITORAL & 109 & NÚMERO & 98 & ALEXANDRE \\
\hline 61 & 205 & PROVISÓRIA & 108 & CASA & 97 & MAIOR \\
\hline 62 & 205 & PSDB & 107 & BÁSICA & 94 & PLANALTO \\
\hline 63 & 202 & CAMPANHA & 107 & RESIDÊNCIA & 92 & CONSELHO \\
\hline 64 & 198 & LEI & 106 & SECRETÁRIO & 92 & OPOSIÇÃO \\
\hline 65 & 196 & SALÁRIO & 105 & ATENÇÃOO & 90 & ATENÇÃO \\
\hline 66 & 195 & ATENÇÃOO & 105 & PRAZO & 90 & PARTIDO \\
\hline 67 & 195 & FAMÍLIA & 104 & CFM & 90 & VALOR \\
\hline 68 & 195 & JUSTIÇA & 104 & GRUPO & 89 & PETISTA \\
\hline 69 & 194 & BOLSA & 103 & PROBLEMA & 89 & PRÉ \\
\hline 70 & 192 & CURSO & 102 & CEARÁ & 87 & CANDIDATO \\
\hline
\end{tabular}

TradTerm, São Paulo, v. 25, Agosto/2015, pp. 199-233 
LuZ, C.; Cambrala, C. N.; GontiJo, E. D. - Monitoramento de terminologia na mídia: o Programa Mais Médicos

\begin{tabular}{llclclc}
71 & 190 & SECRETÁRIO & 101 & DECISÃO & 87 & SUS \\
72 & 187 & CRÍTICA & 101 & ATENDIMENTO & 86 & INÍCIO \\
73 & 185 & BÁSICA & 99 & PREFEITURA & 85 & GRANDE \\
74 & 185 & TEXTO & 98 & ESTADO & 85 & NOVO \\
75 & 181 & CONDIÇ̃̃O & 97 & AVALIAÇÃO & 85 & PEDIDO \\
76 & 181 & NÚMERO & 97 & FORMA & 85 & RECURSO \\
77 & 181 & VIDA & 97 & REGIONAL & 85 & UNIÃO \\
78 & 179 & PLANALTO & 96 & UNIDADE & 84 & EVENTO \\
79 & 179 & UNIÃO & 95 & INSCRIÇÃO & 84 & GESTÃO \\
80 & 177 & FORMA & 94 & REVALIDA & 84 & SECRETÁRIO \\
81 & 177 & PROBLEMA & 94 & SALÁRIO & 83 & AÉCIO \\
82 & 172 & GRUPO & 94 & UNIÃO & 83 & EDUARDO \\
83 & 167 & INÍCIO & 93 & POLÍTICA & 83 & REGIÃO \\
84 & 165 & RECURSO & 91 & PERIFERIA & 82 & LEI \\
85 & 164 & AVALIAÇÃO & 89 & COMISSÃO & 81 & SITUAÇÃO \\
86 & 164 & RELAÇÃO & 89 & TEMPO & 80 & PROPOSTA \\
87 & 163 & CFM & 88 & FAMÍLIA & 78 & BRASÍLIA \\
88 & 162 & GESTÃO & 88 & GERAL & 78 & BÁSICA \\
89 & 161 & DISCURSO & 87 & VINDA & 78 & PASSADO \\
90 & 160 & RESIDÊNCIA & 86 & CRÍTICA & 77 & OBRA \\
91 & 159 & TEMPO & 86 & DIPLOMA & 76 & AUMENTO \\
92 & 158 & UNIDADE & 86 & SENADO & 75 & PRINCIPAL \\
93 & 157 & GOVERNADOR & 85 & PLANALTO & 75 & SISTEMA \\
94 & 156 & GERAL & 85 & RECIFE & 74 & DEM \\
95 & 156 & NOVO & 85 & BOLSA & 74 & PROBLEMA \\
96 & 156 & PARTIDO & 84 & ELEITORAL & 73 & CIVIL \\
97 & 155 & PRAZO & 84 & FINAL & 72 & INTERIOR \\
98 & 154 & REGIÃO & 84 & RIO & 72 & JOSÉ \\
99 & 152 & COMISSÃO & 83 & BASE & 72 & NÚMERO \\
100 & 151 & REVALIDA & 83 & EXAME & 72 & PASTA \\
\hline & & & & &
\end{tabular}

Verifica-se pela TABELA 3 que são poucos os termos-chave da Lei 12.871 que aparecem entre os 100 lexemas nominais mais frequentes. Foram eles (em ordem decrescente):

- No corpus completo (10/28): SAÚDE, PROFISSIONAL, POPULAÇÃO, EDUCAÇÃO, POLÍTICA, SUS, ATENDIMENTO, ATENÇÃO, RECURSO, REGIÃO. 
LUZ, C.; CAmbraiA, C. N.; GontiJo, E. D. - Monitoramento de terminologia na mídia: o Programa Mais Médicos

- No S-A (8/28): SAÚDE, PROFISSIONAL, POPULAÇÃO, EDUCAÇÃO, SUS, ATENÇÃO, ATENDIMENTO e POLÍTICA.

No S-B (10/28): SAÚDE, PROFISSIONAL, POLÍTICA, POPULAÇÃO, EDUCAÇÃO, ATENDIMENTO, ATENÇÃO, SUS, RECURSO e REGIÃO.

Nota-se que os termos-chave que apareceram são bastante genéricos, não abarcando temas tão relevantes para a discussão como DESIGUALDADE, INTEGRAÇÃO, TROCA, PESQUISA, dentre outros.

Infere-se, assim, que, na abordagem da FSP, não foi dada a devida prioridade para aspectos distintivos descritos nos objetivos do PMM.

Não se pode deixar de comentar a alta frequência do lexema CUBANO: a sua frequência é inferior apenas a SAÚDE e PROFISSIONAL dentre os termoschave que aparecem na lista dos 100 mais frequentes no corpus como um todo. Chama a atenção, portanto, que não só os termos-chave que caracterizam os objetivos do PMM sejam tão pouco frequentes (indicando pouca atenção ao que justamente caracteriza a contribuição do PMM), mas também que tenha sido dada tanta atenção ao que não seria prioritário em termos de objetivos (o fato de os médicos serem cubanos).

Considera-se, portanto, que a abordagem da FSP não teria contribuído para focalização do debate sobre o PMM em seus pontos nevrálgicos (expressos pelos objetivos explicitados na Lei).

Esses resultados são compatíveis com os obtidos por Morais et al. (2014), ao analisarem as matérias dos jornais Fol ha de São Paulo e Correio Braziliense entre julho e setembro de 2013 (período abrangido apenas pelo S-A da presente pesquisa): os pesquisadores analisaram 263 publicações da FSP e 101 do Correio Braziliense, com base em sua orientação (otimista/neutra/pessimista), verificando que prevaleceram, na primeira, ( $42 \%$ de títulos) de cunho negativo e, no segundo, $49 \%$ de cunho neutro. No conjunto das publicações dos dois jornais, $49 \%$ das notícias eram de cunho negativo, $28 \%$ neutro e $23 \%$ positivo (Morals et al. 2014: 118-119).

Uma terceira análise possível dos dados da presente pesquisa é considerar apenas os termos-chave: sua frequência em comparação aos demais 
LuZ, C.; Cambrala, C. N.; GontiJo, E. D. - Monitoramento de terminologia na mídia: o Programa Mais Médicos

termos há de revelar a qual dos temas presentes nos objetivos se deu maior ênfase na FSP. Além disso, pode-se também comparar a sua frequência nos S-A e no S-B para verificar se houve mudança em termos de priorização de certos temas.

Apresenta-se a seguir um gráfico com a frequência relativizada dos termos-chave em cada subcorpus e, na sequência, uma tabela com os valores analisados comparando os dois subcorpora, levando em conta sua significância estatística.

Gráfico 3 - Frequência relativizada dos 28 termos-chave na FSP (S-A e S-B)

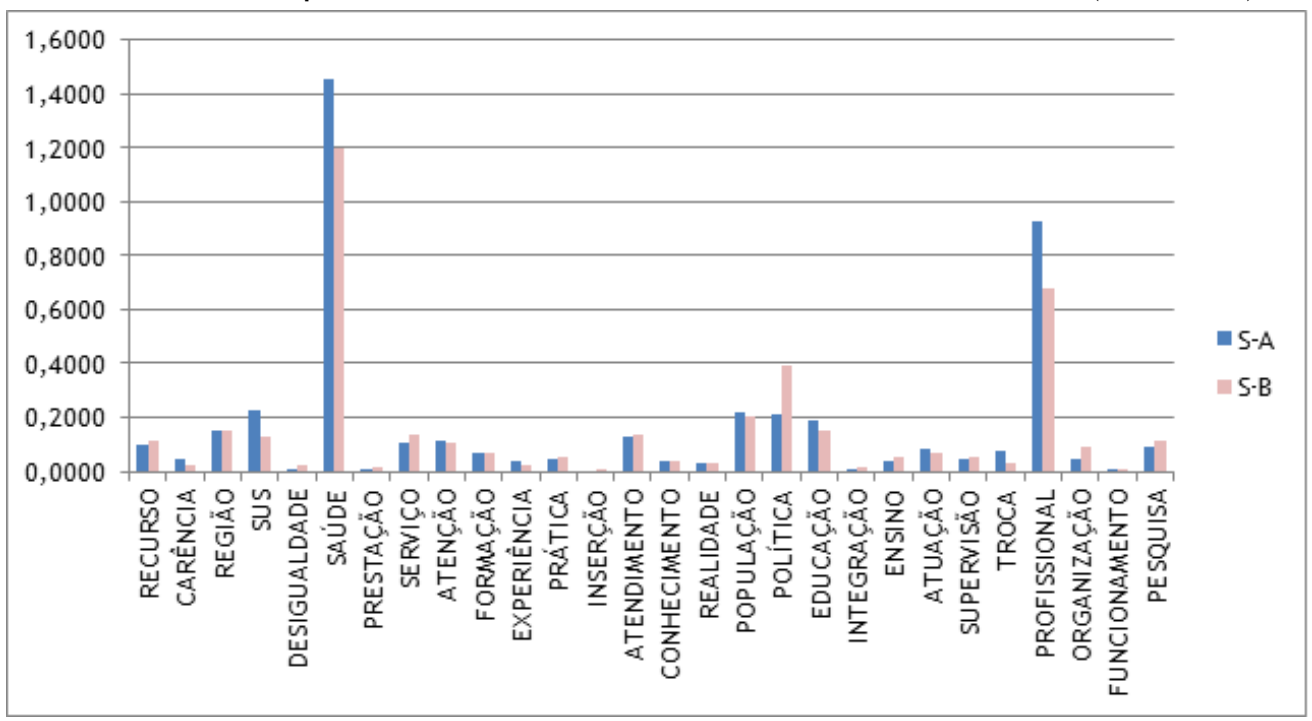


Luz, C.; CambraiA, C. N.; GontiJo, E. D. - Monitoramento de terminologia na mídia: o Programa Mais Médico

Tabela 4 - Significância estatística para Razão de Prevalências (Intervalo de Confiança de 95\%) entre termos-chave no S-A e no S-B

\begin{tabular}{|c|c|c|c|c|c|c|c|c|c|c|c|}
\hline \multicolumn{5}{|c|}{ TERMOS-CHAVE LEI 12.871/13 } & \multicolumn{3}{|c|}{ RAZÃO DAS PREVALÊNCIAS } & \multicolumn{4}{|c|}{ SIGNIFICÂNCIA ESTATIÍSTICA } \\
\hline \multirow{2}{*}{ Lexemas } & \multicolumn{2}{|c|}{ Tokens } & \multicolumn{2}{|c|}{ Frequência } & \multicolumn{2}{|c|}{ Prevalência } & \multirow{2}{*}{$\begin{array}{c}\text { Razão de } \\
\text { Prevalência } \\
\text { (RP) }\end{array}$} & \multirow{2}{*}{ RP (IC 95\%) } & \multicolumn{2}{|c|}{ Limite } & \multirow{2}{*}{ Resultado } \\
\hline & S-A & $S-B$ & S-A & S-B & S-A & S-B & & & Inferior & Superior & \\
\hline RECURSO & 95396 & 83464 & 93 & 93 & 0,0975 & 0,1114 & 1,1430 & 0,3285 & 0,8144 & 1,4715 & Equivalência \\
\hline CARÉNCIA & 95396 & 83464 & 46 & 17 & 0,0482 & 0,0204 & 0,4224 & 0,2350 & 0,1874 & 0,6574 & Redução \\
\hline REGIÃO & 95396 & 83464 & 143 & 123 & 0,1499 & 0,1474 & 0,9831 & 0,2370 & 0,7461 & 1,2201 & Equivalência \\
\hline SUS & 95396 & 83464 & 219 & 109 & 0,2296 & 0,1306 & 0,5689 & 0,1307 & 0,4382 & 0,6996 & Redução \\
\hline DESIGUALDADE & 95396 & 83464 & 4 & 18 & 0,0042 & 0,0216 & 5,1433 & 5,5724 & $-0,4291$ & 10,7157 & Equivalência \\
\hline SAÚDE & 95396 & 83464 & 1388 & 1000 & 1,4550 & 1,1981 & 0,8235 & 0,0669 & 0,7565 & 0,8904 & Redução \\
\hline PRESTAÇÃO & 95396 & 83464 & 6 & 11 & 0,0063 & 0,0132 & 2,0954 & 2,0844 & 0,0110 & 4,1798 & Equivalência \\
\hline SERVIÇO & 95396 & 83464 & 98 & 116 & 0,1027 & 0,1390 & 1,3529 & 0,3638 & 0,9891 & 1,7167 & Equivalência \\
\hline ATENÇÃO & 95396 & 83464 & 105 & 91 & 0,1101 & 0,1090 & 0,9906 & 0,2781 & 0,7125 & 1,2686 & Equivalência \\
\hline FORMAÇÃO & 95396 & 83464 & 63 & 56 & 0,0660 & 0,0671 & 1,0160 & 0,3657 & 0,6502 & 1,3817 & Equivalência \\
\hline EXPERIÊNCIA & 95396 & 83464 & 35 & 16 & 0,0367 & 0,0192 & 0,5225 & 0,3091 & 0,2134 & 0,8315 & Redução \\
\hline PRÁTICA & 95396 & 83464 & 44 & 42 & 0,0461 & 0,0503 & 1,0910 & 0,4613 & 0,6297 & 1,5523 & Equivalência \\
\hline INSERÇÃO & 95396 & 83464 & - & 9 & - & 0,0108 & - & - & - & - & Não se aplica \\
\hline ATENDIMENTO & 95396 & 83464 & 120 & 115 & 0,1258 & 0,1378 & 1,0953 & 0,2802 & 0,8152 & 1,3755 & Equivalência \\
\hline CONHECIMENTO & 95396 & 83464 & 33 & 33 & 0,0346 & 0,0395 & 1,1430 & 0,5515 & 0,5915 & 1,6945 & Equivalência \\
\hline REALIDADE & 95396 & 83464 & 32 & 25 & 0,0335 & 0,0300 & 0,8929 & 0,4672 & 0,4258 & 1,3601 & Equivalência \\
\hline POPULAÇÃO & 95396 & 83464 & 208 & 169 & 0,2180 & 0,2025 & 0,9287 & 0,1885 & 0,7402 & 1,1172 & Equivalência \\
\hline
\end{tabular}

TradTerm, São Paulo, v. 25, Agosto/2015, pp. 199-233

www.usp.br/tradterm

http://www.revistas.usp.br/tradterm/index 
Luz, C.; CambraiA, C. N.; GontiJo, E. D. - Monitoramento de terminologia na mídia: o Programa Mais Médicos

\begin{tabular}{lrlrrrrrrrrr} 
POLITICA & 95396 & 83464 & 203 & 324 & 0,2128 & 0,3882 & 1,8242 & 0,3201 & 1,5042 & 2,1443 & Elevação \\
EDUCAÇÃO & 95396 & 83464 & 180 & 127 & 0,1887 & 0,1522 & 0,8064 & 0,1832 & 0,6233 & 0,9896 & \multicolumn{1}{c}{ Redução } \\
INTEGRAÇÃO & 95396 & 83464 & 5 & 12 & 0,0052 & 0,0144 & 2,7431 & 2,8619 & $-0,1187$ & 5,6050 & Equivalência \\
ENSINO & 95396 & 83464 & 34 & 47 & 0,0356 & 0,0563 & 1,5800 & 0,6972 & 0,8828 & 2,2772 & Equivalência \\
ATUAÇÃO & 95396 & 83464 & 80 & 55 & 0,0839 & 0,0659 & 0,7858 & 0,2698 & 0,5160 & 1,0556 & Equivalência \\
SUPERVISÃO & 95396 & 83464 & 45 & 42 & 0,0472 & 0,0503 & 1,0668 & 0,4486 & 0,6182 & 1,5154 & Equivalência \\
TROCA & 95396 & 83464 & 71 & 28 & 0,0744 & 0,0335 & 0,4507 & 0,1971 & 0,2536 & 0,6479 & Redução \\
PROFISSIONAL & 95396 & 83464 & 886 & 565 & 0,9288 & 0,6769 & 0,7289 & 0,0769 & 0,6520 & 0,8058 & Redução \\
ORGANIZAÇÃO & 95396 & 83464 & 43 & 76 & 0,0451 & 0,0911 & 2,0201 & 0,7556 & 1,2646 & 2,7757 & Elevação \\
FUNCIONAMENTO & 95396 & 83464 & 10 & 4 & 0,0105 & 0,0048 & 0,4572 & 0,5301 & $-0,0729$ & 0,9873 & Redução \\
PESQUISA & 95396 & 83464 & 86 & 92 & 0,0902 & 0,1102 & 1,2227 & 0,3595 & 0,8632 & 1,5822 & Equivalência \\
\hline
\end{tabular}


Luz, C.; CambralA, C. N.; GontiJo, E. D. - Monitoramento de terminologia na mídia: o Programa Mais Médico

Os resultados demonstram que: (a) apresentam redução na frequência os termos CARÊNCIA, SUS, SAÚDE, EXPERIÊNCIA, EDUCAÇÃO, TROCA, PROFISSIONAL e FUNCIONAMENTO; (b) inversamente, há elevação na frequência dos termos-chave POLÍTICA e ORGANIZAÇÃO, no S-B em relação ao S-A; e (c) manteve-se a equivalência entre as demais frequências.

Analisam-se a seguir esses termos que passaram por mudança estatisticamente significativa de frequência, com exceção de FUNCIONAMENTO, cuja baixa frequência foi considerada insuficiente para atender ao procedimento de análise. Para apreender melhor as especificidades do uso desses termos, analisam-se também os colocados (SINCLAIR 1991), ou seja, as lexias mais frequentes na sua margem esquerda e direita.

CARÊNCIA - A redução da frequência desse termo-chave entre S-A e S-B denota, como nos demais casos de redução, que o tema perde espaço na pauta de cobertura do jornal.

Tabela 5 - CARÊNCIA e colocados

\begin{tabular}{|c|c|c|c|c|}
\hline \multirow[b]{2}{*}{ CARÊNCIA } & \multirow[b]{2}{*}{ Colocados } & \multicolumn{2}{|c|}{ SUBCORPORA } & \multirow[b]{2}{*}{ Total 64 (100\%) } \\
\hline & & A 46 & B 17 & \\
\hline \multirow{2}{*}{$\begin{array}{l}\text { Margem } \\
\text { esquerda }\end{array}$} & suprir (a) carência & 06 & 03 & 09 \\
\hline & maior carência & 03 & - & 03 \\
\hline \multirow{3}{*}{$\begin{array}{l}\text { Margem } \\
\text { direita }\end{array}$} & carência (de) médicos & 12 & 08 & 20 \\
\hline & carência (de, desses) profissionais & 14 & 04 & 18 \\
\hline & carência (de) recursos (humanos) & 02 & - & 02 \\
\hline
\end{tabular}

Os colocados mais comuns revelam a motivação básica do PMM: suprir a carência de médicos.

Pode-se imaginar que a redução da frequência do termo-chave CARÊNCIA do S-A para o S-B derive da efetiva implantação do PMM: uma vez implementado o Programa, a questão básica não seria mais a carência, pois a presença dos médicos do Programa já teria começado a sanar o problema. 
Luz, C.; Cambraia, C. N.; GontiJo, E. D. - Monitoramento de terminologia na mídia: o Programa Mais Médico

SUS - Essa sigla forma unidade lexical de largo emprego no campo da saúde pública.

Tabela 6 - SUS e colocados

\begin{tabular}{c|l|c|c|c}
\hline \multirow{2}{*}{ SUS } & \multirow{2}{*}{ Colocados } & \multicolumn{2}{|c|}{ SUBCORPORA } & \multirow{2}{*}{ Total 328 (100\%) } \\
\cline { 3 - 4 } & & A 219 & B 109 & \\
\hline \multirow{3}{*}{ Margem esquerda } & serviços prestados (no) SUS & 13 & - & 13 \\
& dois anos (no) SUS & 09 & 02 & 11 \\
& trabalho (no) SUS & 15 & 01 & 16 \\
\hline Margem direita & SUS funciona & 03 & - & 03 \\
\hline
\end{tabular}

Os colocados em sua margem esquerda (serviços prestados, dois anos, trabalho) evidenciam que o termo-chave era mencionado, sobretudo, quando se fazia referência à questão do segundo ciclo na formação médica, inicialmente previsto na MP 621 e retirado da Lei 12.871 pelo Congresso Nacional, que previa dois anos de trabalho/serviços prestados ao SUS como condição para se diplomar os residentes dos cursos de medicina.

Assim, o decréscimo de SUS estaria relacionado à supressão da proposta de segundo ciclo quando da sanção da Lei.

SAÚDE - Esse termo-chave, que também passou por redução de frequência de $S-A$ para $S-B$, é naturalmente o mais frequente dentre os termoschave analisados, já que designa o próprio campo semântico em que se inserem os demais.

Tabela 7 - SAÚDE e colocados

\begin{tabular}{|c|c|c|c|c|}
\hline \multirow[b]{2}{*}{ SAÚDE } & \multirow[b]{2}{*}{ Colocados } & \multicolumn{2}{|c|}{ SUBCORPORA } & \multirow{2}{*}{$\begin{array}{c}\text { Total } 2388 \\
\quad(100 \%)\end{array}$} \\
\hline & & $\begin{array}{c}A \\
1388\end{array}$ & $\begin{array}{c}B \\
1000\end{array}$ & \\
\hline \multirow{2}{*}{ Margem esquerda } & Ministro (da) Saúde & 65 & 84 & 149 \\
\hline & Ministério (da) Saúde & 312 & 157 & 469 \\
\hline \multirow{2}{*}{ Margem direita } & saúde pública & 52 & 32 & 84 \\
\hline & saúde (da) família & 38 & 25 & 63 \\
\hline
\end{tabular}


Luz, C.; CambralA, C. N.; GontiJo, E. D. - Monitoramento de terminologia na mídia: o Programa Mais Médico

Se, por um lado, causa surpresa a diminuição da referência ao Ministério da Saúde (expressão que abrange as ocorrências mais numerosas do termochave em questão), pois o PMM é gerenciado por esse Ministério; por outro, entende-se perfeitamente porque houve aumento da frequência do termochave na expressão Ministro da Saúde: o aumento diz respeito à mudança de Ministro da Saúde em 3 de fevereiro de 2014, para que o ministro anterior, Alexandre Padilha, se candidatasse ao cargo de governador de São Paulo.

EXPERIÊNCIA - Também esse termo-chave sofreu redução do S-A para o S-B. Os colocados revelam uma questão interessante.

Tabela 8 - EXPERIÊNCIA e colocados

\begin{tabular}{c|l|c|c|c}
\hline \multirow{2}{*}{ EXPERIÊNCIA } & \multirow{2}{*}{ Colocados } & \multicolumn{2}{|c|}{ SUBCORPORA } & \multirow{2}{*}{ Total } \\
\cline { 3 - 4 } & & $\mathrm{A}$ & $\mathrm{B}$ & $51(100 \%)$ \\
& & 35 & 16 & \\
\hline \multirow{2}{*}{ Margem esquerda } & anos (de) experiência & 09 & - & 09 \\
& primeira experiência & 02 & - & 02 \\
\hline \multirow{2}{*}{ Margem direita } & experiência (em) medicina & 03 & - & 03 \\
& experiência (em) missões (internacionais) & 04 & 01 & 05 \\
\hline
\end{tabular}

É digno de nota assinalar que os colocados não se voltam para o objetivo previsto na Lei 12.871 em que o termo-chave ocorre: "proporcionar maior experiência no campo de prática médica durante o processo de formação". Antes, relacionam-se com a experiência dos médicos de outros países que chegavam ao Brasil e que, naquele momento, tinham suas habilidades $\mathrm{e}$ bagagem profissional colocados em pauta. Supõe-se que, com a progressiva aceitação da população em relação aos médicos estrangeiros (revelada pelas pesquisas), a discussão sobre a sua experiência prévia tenha arrefecido. 
Luz, C.; Cambraia, C. N.; GontiJo, E. D. - Monitoramento de terminologia na mídia: o Programa Mais Médico

TROCA - 0 objetivo do qual esse termo-chave foi extraído era o de "promover a troca de conhecimentos e experiências entre profissionais da saúde brasileiros e médicos formados em instituições estrangeiras". Como se pode comprovar pelos colocados mais frequentes, não foram esses os sentidos majoritariamente contemplados pelas publicações.

Tabela 9 - TROCA e colocados

\begin{tabular}{c|l|c|c|c}
\hline \multirow{2}{*}{ TROCA } & Colocados & \multicolumn{2}{|c|}{ SUBCORPORA } & \multirow{2}{*}{ Total } \\
\cline { 3 - 4 } & & $\mathrm{A}$ & $\mathrm{B}$ & $99(100 \%)$ \\
\hline Margem esquerda & moeda de troca & 04 & - & 04 \\
\hline \multirow{2}{*}{ Margem direita } & troca (de, os) médicos & 07 & 03 & 10 \\
& troca profissional & 04 & 01 & 04 \\
\hline
\end{tabular}

A expressão moeda de troca marcou o período de discussão (e negociações) em torno da MP 621 no Congresso Nacional. Já troca de médicos ou profissional relaciona-se ao fato de as entidades representativas dos médicos denunciarem municípios que estariam trocando médicos brasileiros das suas equipes de atenção básica (remunerados pelo Piso de Atenção Básica- PAB, formados por repasses federais, mas também por verbas municipais) por aqueles do PMB, custeados exclusivamente pelo Ministério da Saúde.

PROFISSIONAL - Esse termo-chave, que ocupa a segunda posição geral entre seus pares, funciona como base na composição de lexemas complexos no corpus, tais como equipe multiprofissional, contingente profissional, entidade profissional, exercício profissional. Teve sua frequência reduzida entre os subcorpora.

Tabela 10 - PROFISSIONAL e colocados

\begin{tabular}{c|c|c|c|c}
\hline \multirow{2}{*}{ PROFISSIONAL } & \multirow{3}{*}{ Colocados } & \multicolumn{2}{|c|}{ SUBCORPORA } & \multirow{2}{*}{ Total } \\
\cline { 3 - 4 } & & $\mathrm{A}$ & $\mathrm{B}$ & 1451 \\
& & 886 & 565 & $(100 \%)$ \\
\hline Margem esquerdan & registro profissional & 17 & 05 & 22
\end{tabular}


Luz, C.; CAmbraiA, C. N.; Gontijo, E. D. - Monitoramento de terminologia na mídia: o Programa Mais Médico

\begin{tabular}{lllll} 
& levar profissionais & 16 & 06 & 22 \\
\hline \multirow{3}{*}{ Margem direita } & profissionais (da, de, em) saúde & 52 & 33 & 85 \\
& profissionais formados & 41 & 06 & 47 \\
& profissionais estrangeiros & 37 & 14 & 51 \\
\hline
\end{tabular}

As combinações registro profissional e levar profissionais remetem à primeira fase do PMM e do PMB, quando estava em discussão a legitimidade para a emissão do registro para o exercício profissional e a proposta de se enviar médicos para as periferias e regiões do interior do país. Já as combinações profissionais formados e profissionais estrangeiros assinalam a preocupação no primeiro período analisado com a questão da formação e origem dos médicos que viriam ao Brasil.

EDUCAÇÃO - O objetivo expresso pela Lei 12.871 em relação a esse termo-chave ("fortalecer a política de educação permanente com a integração ensino-serviço, por meio da atuação das instituições de educação superior na supervisão acadêmica das atividades desempenhadas pelos médicos") é parcialmente atendido pelos colocados que o acompanham.

Tabela 11 - EDUCAÇÃO e colocados

\begin{tabular}{|c|c|c|c|c|}
\hline \multirow[b]{2}{*}{ EDUCAÇÃO } & \multirow[b]{2}{*}{ Colocados } & \multicolumn{2}{|c|}{ SUBCORPORA } & \multirow{2}{*}{$\begin{array}{c}\text { Total } 307 \\
(100 \%)\end{array}$} \\
\hline & & A 180 & B 127 & \\
\hline \multirow{2}{*}{ Margem esquerda } & Ministério (da) Educação & 26 & 20 & 46 \\
\hline & saúde (e) educação & 13 & 10 & 23 \\
\hline \multirow{2}{*}{ Margem direita } & educação (e, em, na) saúde & 21 & 7 & 28 \\
\hline & educação superior & 11 & 7 & 18 \\
\hline
\end{tabular}

Assim, Ministério da Educação e Educação Superior denotam a formulação e condução conjunta pelos ministérios da Saúde e Educação no PMM, bem como a participação das instituições de educação/ensino superior na capacitação dos médicos intercambistas. Educação (e, em, na) saúde, denota, 
LUZ, C.; Cambrala, C. N.; GontiJo, E. D. - Monitoramento de terminologia na mídia: o Programa Mais Médico

sobretudo, a Secretaria de Gestão do Trabalho e Educação em Saúde (SGTES), responsável, no âmbito do MS, pelo PMM. Saúde e educação expressam significados mais específicos, porque estão relacionados aos cinco pactos anunciados pela Presidência da República, após as manifestações de junho de 2013, sendo as duas pastas muito citadas como destino dos recursos a serem obtidos pelos royalties do Pré-Sal'.

POLÍTICA - Um dos dois termos-chave que não integraram a lista dos 100 lexemas mais frequentes no S-A e irá se situar entre os 32 mais frequentes no S-B, com notável crescimento.

Tabela 12 - POLÍTICA e colocados

\begin{tabular}{|c|c|c|c|c|}
\hline \multirow[b]{2}{*}{ POLÍTICA } & \multirow[b]{2}{*}{ Colocados } & \multicolumn{2}{|c|}{ SUBCORPORA } & \multirow{2}{*}{$\begin{array}{c}\text { Total } 527 \\
(100 \%)\end{array}$} \\
\hline & & $\begin{array}{c}A \\
203\end{array}$ & $\begin{array}{c}B \\
324\end{array}$ & \\
\hline \multirow{3}{*}{ Margem esquerda } & reforma política & 16 & 36 & 52 \\
\hline & articulação política & 06 & 02 & 08 \\
\hline & asilo político & 06 & 12 & 18 \\
\hline \multirow{2}{*}{ Margem direita } & política pública & 22 & 06 & 28 \\
\hline & política partidária & 05 & - & 05 \\
\hline
\end{tabular}

Indiferente ao objetivo expresso na Lei 12.871 ("fortalecer a política de educação"), esse termo-chave, quando examinado em relação aos seus colocados, apresenta questões interessantes. Ele teve sua frequência dentre as que mais cresceram entre S-A e S-B: as expressões em que mais ocorre são reforma política, acompanhando as repercussões das manifestações de rua de junho de 2013, e asilo político, referência à deserção de alguns médicos cubanos nos primeiros meses de 2014.

1 Disponível em: www.brasil.gov.br/governo/2013/10/dilma-fala-sobre-cumprimento-doscinco-pactos-propostos-em-junho. Acesso em 07 abr. 2015. 
Luz, C.; CambralA, C. N.; GontiJo, E. D. - Monitoramento de terminologia na mídia: o Programa Mais Médico

ORGANIZAÇÃO - Por fim, novamente, tem-se um termo-chave que apresentou elevação na frequência, embora seu uso não reflita o sentido presente pelo objetivo da Lei 12.871 do qual foi extraído: "aperfeiçoar médicos para atuação nas políticas públicas de saúde do País e na organização e no funcionamento do SUS".

Tabela 13 - ORGANIZAÇÃO e colocados

\begin{tabular}{|c|c|c|c|c|}
\hline \multirow[b]{2}{*}{ ORGANIZAÇÃO } & \multirow[b]{2}{*}{ Colocados } & \multicolumn{2}{|c|}{ SUBCORPORA } & \multirow{2}{*}{$\begin{array}{c}\text { Total } 119 \\
(100 \%)\end{array}$} \\
\hline & & 43 & B 76 & \\
\hline \multirow[t]{2}{*}{ Margem esquerda } & $\begin{array}{l}\text { OPAS (braço da) ORGANIZAÇÃO (MUNDIAL } \\
\text { DE SAÚDE) }\end{array}$ & 16 & 33 & 49 \\
\hline & ORGANIZAÇÃO PAN-AMERICANA & 14 & 34 & 48 \\
\hline \multirow[t]{2}{*}{ Margem direita } & ORGANIZAÇÃO MUNDIAL (DA/DE SAÚDE) & 11 & 10 & 21 \\
\hline & ORGANIZAÇÕES SOCIAIS & 04 & 03 & 07 \\
\hline
\end{tabular}

Majoritariamente, os colocados mais frequentes formam com o termochave nomes próprios de entidades: Organização Mundial de Saúde e Organização Pan-Americana de Saúde. Essas expressões põem em evidência a polêmica intermediação de entidades no acordo internacional para a contratação dos médicos cubanos, que receberiam apenas uma parcela dos recursos repassados ao governo do seu país de origem.

\section{Considerações finais}

Os dados coletados confirmaram as hipóteses de trabalho: (a) primeiramente, a ausência da maioria dos termos-chave dentre os 100 lexemas mais frequentes revelou que os objetivos da Lei $n^{0} 12.871$ (representados na análise pelos termos-chave) foram pouco contemplados nas publicações da FSP, demostrando assim uma cobertura pouco produtiva em termos de discussão sobre saúde pública; e (b) em segundo lugar, foi possível verificar ter havido algumas mudanças entre o período de cobertura anterior à publicação da 
LuZ, C.; Cambrala, C. N.; GontiJo, E. D. - Monitoramento de terminologia na mídia: o Programa Mais Médico

referida lei ( 22 de outubro) e o período posterior (mudanças perceptíveis pela alteração na frequência de alguns termos-chave), revelando que a cobertura se modificou provavelmente em função da progressiva aprovação da população em relação ao PMM, conforme informam as pesquisas de sondagem de opinião realizadas.

Uma questão que emerge naturalmente em relação à abordagem adotada é sua relevância. Por que, por exemplo, uma análise sobre o referido tema não pode ser simplesmente feita pela leitura de cada uma das publicações?

Uma das vantagens do método aqui adotado é a exaustividade dos dados. Análises puramente qualitativas tendem a ser suscetíveis a impressões que um ou outro texto exerce sobre o leitor-pesquisador, induzindo assim a dar maior destaque a uma publicação, ainda que a forma de tratamento do tema nela possa ter ocorrido apenas uma vez ou ainda ter sido bastante rara.

Veja-se, por exemplo, que não foram todos os termos-chave do presente estudo que apresentaram mudança de frequência estatisticamente relevante. Logo, dar a esses termos estatisticamente não significativos especial atenção em um dado momento levaria à falsa impressão de que eles seriam representativos, embora sua frequência tenha sido equivalente ao longo de todo o período de análise.

A presente abordagem tem como objetivo contribuir para a construção de modelos de análise de conteúdos mais automatizados. Embora obviamente não se considere que a automatização será capaz de produzir interpretações sócio-históricas de um tema (dependente única e exclusivamente do pesquisador-leitor), ela há de permitir um trabalho rigoroso com um volume cada vez maior de dados. Um simples exemplo para demonstrar que o processamento automatizado de informação ainda está longe de ter um modelo eficiente é o próprio clipping do Ministério da Saúde sobre o PMM: não se sabe como é feita a coleta das reportagens, mas, na fase preliminar deste estudo, constatou-se sua precariedade em relação ao número real de publicações disponíveis na FSP. Assim, qualquer análise com os dados do clipping seria necessariamente parcial ou ainda enviesada. 
Luz, C.; CambralA, C. N.; GontiJo, E. D. - Monitoramento de terminologia na mídia: o Programa Mais Médico

Apesar de esta experiência ter gerado resultados relevantes, não se pode deixar de mencionar algumas limitações.

Em primeiro lugar, a questão da escolha dos termos-chave parece ser a fragilidade de análises por via lexical. A proposta aqui adotada foi a de examinar o PMM levando em conta os objetivos expressos textualmente na lei, o que gerou resultados interessantes. Entretanto, há outros temas (expressos por lexemas ausentes dos objetivos da lei) que também mereceriam ser contemplados, tais como: PACIENTE, USUÁRIO, DOENTE, CONSELHO (MUNICIPAL, ESTADUAL e NACIONAL) DE SAÚDE.

Em segundo lugar, há que se incluir na discussão o problema de variação terminológica: os termos-chave eleitos na presente pesquisa apresentam variantes (entendidas como formas diferentes veiculando mesmo conteúdo)? Em caso afirmativo, a não consideração dessas variantes (em função da obediência estrita ao método de analisar apenas o que está no texto da lei) exclui a percepção da presença de um mesmo tema em outros textos. Para esse problema, pode-se invocar a tradicional visão de que não há sinonímia perfeita: assim, o simples fato de se ter optado pelo termo $A$ e não pelo $B$ já seria informação significativa; mais concretamente, termos como ATENÇÃO (BÁSICA) e ATENDIMENTO (BÁSICO), embora possam parecer equivalentes, apresentam diferenças de uso que justificariam serem tratados individualmente.

Mesmo com essas limitações, o método de monitoramento computacional por meio da terminologia mostrou-se interessante para detectar presenças e ausências relevantes quando se trata da discussão de temas especializados na cobertura da mídia, como comprovam os resultados obtidos pela análise do corpus da Folha de São Paulo. Assim, acredita-se que este método pode ser um guia útil para a apreensão dos sentidos efetivamente produzidos pelos meios de comunicação em torno de questões de elevado interesse para as comunidades técnico-científicas, merecendo ser mais explorado e testado. 
Luz, C.; Cambraia, C. N.; GontiJo, E. D. - Monitoramento de terminologia na mídia: o Programa Mais Médico

\section{Referências bibliográficas}

ANJ [ASSOCIAÇÃo NACIONAL DOS JORNAIS]. Os maiores jornais do brasil de circulação paga, por ano. Disponível em: anj.org.br/maiores-jornais-do-brasil. Acesso em: 04 dez. 2014.

BARRos, L. A. Curso básico de terminologia. São Paulo: Edusp, 2004.

BIDERMAN, M. T. Teoria lingüística: teoria lexical e lingüística computacional. 2.ed. São Paulo: Martins Fontes, 2001.

Blog Cadê o Médico, 2013. Número de médicos cresce, mas eles estão mal distribuídos pelo país. Disponível em: www.cadeomedico.blogspot.com.br. Acesso em: 21 jan. 2015.

BRASIL. Constituição (1988). Constituiç̧ão [da] República Federativa do Brasil. Brasília: Senado Federal, $1988 . \quad$ Disponível em: www.planalto.gov.br/ccivil_03/constituicao/constituicaocompilado.htm. Acesso em: 23 jan. 2015.

BRASIL. Lei $n^{\circ} 12.871$, de 22 de outubro de 2013. Institui o Programa Mais Médicos, altera as Leis no 8.745, de 9 de dezembro de 1993, e oㅜ 6.932, de 7 de julho de 1981, e dá outras providências. Brasília, 2013a. Disponível em: www.planalto.gov.br/ccivil_03/_ato2011-2014/2013/Lei/L12871.htm. Acesso em: 21 jan. 2015.

BRASIL. Medida provisória $n^{\circ}$ 621, de 8 de julho de 2013. Institui o Programa Mais Médicos e dá outras providências. Brasília, 2013b. Disponível em: www.planalto.gov.br/ccivil_03/_ato2011-2014/2013/mpv/mpv621.htm.

Acesso em: 21 jan. 2015.

BRASIL. Projeto de lei de conversão $n^{\circ} 26$ de 2013. Institui o Programa Mais Médicos, altera as Leis $n^{\circ} 8.745$, de 9 de dezembro de 1993, e $n^{\circ} 6.932$, de 7 de julho de 1981, e dá outras providências. Brasília, 2013c. Disponível em: www.senado.gov. br/atividade/materia/getPDF.asp?t=138030\&tp=1. Acesso em: 21 jan. 2015.

BRASIL. Decreto $n^{\circ}$ 8.126, de 22 de outubro de 2013. Dispõe sobre a emissão do registro único e da carteira de identificação para os médicos intercambistas participantes do Projeto Mais Médicos para o Brasil, de que trata a Lei no 12.871, de 22 de outubro de 2013. Brasília, 2013d. Disponível em: www.planalto.gov.br/ccivil_03/_ato2011-2014/2013/Decreto/D8126.htm. Acesso em: 21 jan. 2015.

BRASIL. Parecer $n^{\circ} 1.143$ de 2013. Redação final do Projeto de Lei de Conversão $n^{\circ}$ 26, de 2013 (Medida Provisória ${ }^{\circ}$ 621, de 2013). Brasília, 2013e. Disponível em: legis.senado.leg.br/mateweb/arquivos/mate-pdf/138602.pdf. Acesso em: 21 jan. 2015. 
Luz, C.; CambralA, C. N.; GontiJo, E. D. - Monitoramento de terminologia na mídia: o Programa Mais Médico

CABRÉ, M. T. La terminología: representación y comunicación; elementos para una teoría de base comunicativa y otros artículos. Barcelona: IULA/Universitat Pompeu Fabra, 1999. (Sèrie Monografies, 3)

Dab [Departamento De Atenção Básica]. Ministério da Saúde. Ministério da Saúde amplia Mais Médicos em 1.500 municípios. Disponível em: portalsaude.saude.gov.br/index.php/cidadao/principal/agencia-saude/16228ministerio-da-saude-amplia-mais-medicos-em-1-500-municipios. Acesso em: 22 jan. 2015.

DEVER, G. E. A. Epidemiology in health services management. New York: Aspen, 1984.

KRIEGER, M. da G. Terminologia revisitada. DELTA, v. 16, n. 2, 2000, pp. 209228. Disponível em: www.scielo.br/pdf/delta/v16n2/a01v16n2.pdf. Acesso em: 04 abr. 2015.

LÉON, J. A lingüística de corpus: história, problemas, legitimidade. Filologia e Linguística Portuguesa, n. 8, 2006, pp. 51-81. Disponível em: www.revistas.usp.br/flp/article/view/59745. Acesso em: 14 Jul. 2015.

Luz, C. A. O Programa Mais Médicos em uma abordagem lexical: representação social e repercussão científica. 2015. Dissertação (Mestrado em Saúde Pública) - Universidade Federal de Minas Gerais, 2015.

MORAIS, I. et al. Jornais Folha de São Paulo e Correio Braziliense: o que dizem sobre o Programa Mais Médicos?. Revista da Escola de Enfermagem da USP, São Paulo, v. 48, n. spe2, 2014, pp. 107-115. Disponível em: www.scielo.br/scielo.php?script=sci_arttext\&pid $=\$ 0080$ -

62342014000800107\&lng=en\&nrm=iso. Acesso em: 14 jul. 2015.

RousSEFF, D. Discurso da presidenta da república, Dilma Rousseff, durante cerimônia de abertura do encontro nacional com os novos prefeitos e prefeitas. Brasília, 2013. Disponível em: www2.planalto.gov.br/acompanhe-oplanalto/discursos/discursos-da-presidenta/discurso-da-presidenta-darepublica-dilma-rousseff-durante-cerimonia-de-abertura-do-encontronacional-com-os-novos-prefeitos-e-prefeitas. Acesso em: 21 jan. 2015.

SANCHEZ, A. Definicion e historia de los corpus. In: SANChEz, A. et al (org.). CUMBRE - Corpus Linguistico de Espanol Conteporaneo. Madrid: SGEL, 1995.

SARDINHA, T. B. Lingüística de corpus: histórico e problemática. DELTA, São Paulo, v. 16, n. 2, 2000, pp. 323-367. Disponível em: www.scielo.br/scielo.php?script=sci_arttext\&pid=S0102$44502000000200005 \&$ lng=en\&nrm=iso. Acesso em: 26 jan. 2015.

SINCLAIR, J. M. Corpus, concordance, collocation. Oxford: Oxford University Press, 1991. 